Disclosure of Interests: Abdulla Watad: None declared, Nicola Luigi Bragazzi: None declared, Dennis McGonagle Consultant for: Lilly, Novartis UCB, Speakers bureau: Lilly, Novartis UCB, Doron Comanesther: None declared, Arnon Cohen Grant/research support from: Prof. Arnon Cohen received research grants from Janssen, Novartis and AbbVie and Sanofi, Consultant for: Prof. Arnon Cohen served as a consultant, advisor for AbbVie; Amgen; Boehringer Ingelheim; Dexcel pharma; Janssen, Lilly; Neopharm; Novartis, Perrigo; Pfizer; Rafa; Sanofi, Speakers bureau: Prof. Arnon Cohen served as speaker for AbbVie; Amgen; Boehringer Ingelheim; Dexcel pharma; Janssen, Lilly; Neopharm; Novartis, Perrigo; Pfizer; Rafa; Sanofi, Howard Amital Grant/research support from: Pfizer, AbbVie, Janssen, Grant/research support from: Pfizer, AbbVie, Janssen, Consultant for: Pfizer, Merck Sharp \& Dohme, Consultant for: Pfizer, Merck Sharp \& Dohme, Speakers bureau: Pfizer, Merck Sharp \& Dohme, Janssen, Sanofi, Bristol-Myers Squibb, Abbvie, Neopharm, Speakers bureau: Pfizer, Merck Sharp \& Dohme, Janssen, Sanofi, Bristol-Myers Squibb, Abbvie, Neopharm

DOI: 10.1136/annrheumdis-2019-eular.1088

\section{FRI0621 ASSOCIATIONS BETWEEN ORGAN INVOLVEMENTS AND GENDER, ALLERGY, AND MALIGNANCY IN 166 PATIENTS WITH IGG4-RELATED DISEASE}

Hajime Yoshifuji ${ }^{1}$, Mirei Shirakashi ${ }^{1}$, Yuzo Kodama ${ }^{2}$, Tsutomu Chiba ${ }^{3}$, Motohisa Yamamoto ${ }^{4}$, Hiroki Takahashi ${ }^{4}$, Kazushige Uchida ${ }^{5}$, Kazuichi Okazaki ${ }^{5}$, Tetsuya Ito $^{6}$, Shigeyuki Kawa ${ }^{7}$, Kazunori Yamada ${ }^{8}$, Mitsuhiro Kawano ${ }^{8}$, Shintaro Hirata ${ }^{9}$, Yoshiya Tanaka ${ }^{10}$, Masafumi Moriyama ${ }^{11}$, Seiji Nakamura ${ }^{11}$, Terumi Kamisawa ${ }^{12}$, Shoko Matsui ${ }^{13}$, Hiroto Tsuboi ${ }^{14}$, Takayuki Sumida ${ }^{14}$, Motoko Shibata $^{15}$, Hiroshi Goto ${ }^{15}$, Yasuharu Sato ${ }^{16}$, Tadashi Yoshino ${ }^{16}$ Tsuneyo Mimori ${ }^{1}$. 'Kyoto University, Kyoto, Japan; ${ }^{2}$ Kobe University, Kobe, Japan ${ }^{3}$ Kansai Electric Power Hospital, Osaka, Japan; ${ }^{4}$ Sapporo Medical University, Sapporo, Japan; ${ }^{5}$ Kansai Medical University, Hirakata, Japan; ${ }^{6}$ Shinshu University, Matsumoto, Japan; ${ }^{7}$ Matsumoto Dental University, Shiojiri, Japan; ${ }^{8}$ Kanazawa University, Kanazawa, Japan; ${ }^{9}$ Hiroshima University, Hiroshima, Japan; ${ }^{10}$ University of Occupational and Environmental Health, Fukuoka, Japan; ${ }^{11}$ Kyushu University, Fukuoka, Japan; ${ }^{12}$ Tokyo Metropolitan Komagome Hospital, Tokyo, Japan; ${ }^{13}$ University of Toyama, Toyama, Japan; ${ }^{14}$ University of Tsukuba, Tsukuba, Japan; ${ }^{15}$ Tokyo Medical University, Tokyo, Japan; ${ }^{16}$ Okayama University,

Okayama, Japan

Background: Symptomatic differences between male and female patients with IgG4-related disease (IgG4-RD) have been reported [1]. Associations between IgG4-RD and allergy and malignancy have also been reported, although they are controversial.

Objectives: We previously analyzed the treatment course of IgG4-RD using a multi-center cohort [2]. In the present study, we investigated the associations between organ symptoms and gender, allergic diseases, and malignancies.

Methods: Data of 166 patients with a definitive diagnosis of IgG4-RD were retrospectively analyzed.

Results: The cohort consisted of 108 men (65\%) and 58 women (35\%). Most frequently, the submandibular gland (52\%), pancreas $(46 \%)$, lachrymal gland $(43 \%)$, and lymph node $(38 \%)$ were affected. Furthermore, we assessed the frequencies of female sex, allergy, and malignancy in patients with each affected organ (Table 1). The organs with high frequencies of women included the lachrymal gland (50\%), lungs (44\%), and submandibular gland $(43 \%)$. Those with low frequencies of women included the thyroid gland $(0 \%)$, retroperitoneum $(17 \%)$, and para-aorta (19\%). In addition, allergic diseases were found in 60 patients $(36 \%)$ (Fig. 1A). The organs with high frequencies of allergy included the thyroid gland $(50 \%)$, submandibular gland $(47 \%)$, and lachrymal gland $(40 \%)$. Those with low frequencies of allergy were the para-aorta $(13 \%)$, prostate gland $(30 \%)$, and retroperitoneum (31\%). Malignancies were found in 23 (14\%) patients (Fig. 1B). Organs with high frequencies of malignancy included the para-aorta (38\%), prostate gland $(30 \%)$, and retroperitoneum $(21 \%)$. In comparison, those with low frequencies of malignancy included the thyroid gland $(0 \%)$, lungs $(8 \%)$, and kidney $(8 \%)$.

Conclusion: Craniocervical organ involvement was associated with female sex and presence of allergic diseases, suggesting that allergy may contribute to onset of IgG4-RD in some patients. Abdominal organ involvement was associated with male sex and presence of malignancies, suggesting that malignancy may in part contribute to IgG4-RD.
REFERENCE:

[1] Wang, et al., Rheumatology, 2018. [2] Shirakashi, et al., Sci Rep, 2018.

Table 1. Frequencies of female sex, allergy, and malignancy in patients with indicated affected organ.

\begin{tabular}{|c|c|c|c|c|c|c|}
\hline & $\begin{array}{c}\text { Women } \\
(\%)\end{array}$ & *1 & $\begin{array}{c}\text { Allergy } \\
(\%)\end{array}$ & *2 & $\begin{array}{c}\text { Malignancy } \\
(\%)\end{array}$ & *3 \\
\hline Eye orbit & 23 & $L$ & 38 & $\mathbf{H}$ & 15 & H \\
\hline Lachrymal gl. & 50 & $\mathbf{H}$ & 40 & $\mathbf{H}$ & 11 & L \\
\hline Parotid gl. & 36 & $\mathbf{H}$ & 36 & - & 18 & H \\
\hline $\begin{array}{l}\text { Submandibular } \\
\text { gl. }\end{array}$ & 43 & $\mathbf{H}$ & 47 & $\mathbf{H}$ & 13 & L \\
\hline Thyroid gl. & 0 & $\mathrm{~L}$ & 50 & $\mathbf{H}$ & 0 & L \\
\hline Lung & 44 & $\mathbf{H}$ & 32 & $\mathrm{~L}$ & 8 & L \\
\hline Pancreas & 31 & $\mathrm{~L}$ & 32 & $\mathrm{~L}$ & 18 & H \\
\hline Bile duct & 23 & $\mathrm{~L}$ & 33 & $\mathrm{~L}$ & 15 & H \\
\hline Kidney & 40 & $\mathbf{H}$ & 36 & - & 8 & L \\
\hline Retroperitoneum & 17 & $\mathrm{~L}$ & 31 & $\mathrm{~L}$ & 21 & H \\
\hline Para-aorta & 19 & $\mathrm{~L}$ & 13 & $\mathrm{~L}$ & 38 & H \\
\hline Prostate gl. & 0 & $L$ & 30 & $\mathrm{~L}$ & 30 & H \\
\hline Lymph node & 41 & $\mathbf{H}$ & 38 & $\mathbf{H}$ & 13 & L \\
\hline Total & 35 & - & 36 & - & 14 & - \\
\hline
\end{tabular}

${ }^{*} \mathbf{H}, \mathrm{L}$, or "-" are marked if the frequency is higher, lower, or no change respectively, when compared to the total frequencies of female sex $(35 \%)^{1 *}$, allergy $(36 \%)^{2 *}$, and malignancy $(14 \%)^{3 *}$
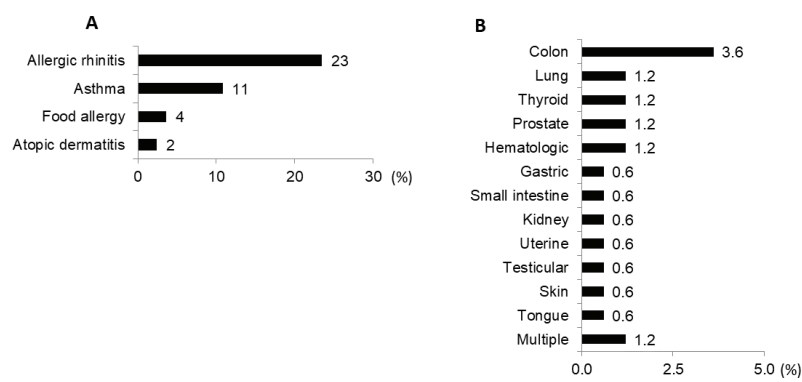

Figure 1. Frequency of allergic diseases (A) and malignancies (B) in 166 patients with IgG4-RD.

Disclosure of Interests: Hajime Yoshifuji: None declared, Mirei Shirakashi: None declared, Yuzo Kodama: None declared, Tsutomu Chiba: None declared, Motohisa Yamamoto: None declared, Hiroki Takahashi: None declared, Kazushige Uchida: None declared, Kazuichi Okazaki: None declared, Tetsuya Ito: None declared, Shigeyuki Kawa: None declared, Kazunori Yamada: None declared, Mitsuhiro Kawano: None declared, Shintaro Hirata Grant/research support from: Eli Lilly, UCB, Consultant for: Bristol-Myers Squibb, Jansen, UCB, Paid instructor for: AbbVie, Eisai, Tanabe-Mitsubishi, Speakers bureau: AbbVie, Astellas, Ayumi, BristolMyers Squibb, Chugai, Eisai, Eli Lilly, Jansen, Kissei, Pfizer, Sanofi, Takeda, Tanabe-Mitsubishi, UCB, Yoshiya Tanaka Grant/research support from: Abbvie, Astellas, Bristol-Myers Squibb, Chugai, Daiichi-Sankyo, Eisai, Mitsubishi-Tanabe, MSD, Ono, Taisho-Toyama, Takeda, Speakers bureau: Abbvie, Asahi-kasei, Astellas, Bristol-Myers Squibb, Chugai, Daiichi-Sankyo, Eli Lilly, Eisai, Glaxo-Smithkline, Janssen, Mitsubishi-Tanabe, Novartis, Pfizer Japan Inc, Sanofi, Takeda, UCB, YL Biologics, Masafumi Moriyama: None declared, Seiji Nakamura: None declared, Terumi Kamisawa: None declared, Shoko Matsui: None declared, Hiroto Tsuboi: None declared, Takayuki Sumida Grant/research support from: Bristol-Myers Squibb, Speakers bureau: Bristol-Myers Squibb, Motoko Shibata: None declared, Hiroshi Goto: None declared, Yasuharu Sato: None declared, Tadashi Yoshino: None declared, Tsuneyo Mimori: None declared DOI: 10.1136/annrheumdis-2019-eular.1264 


\section{Diagnostics and imaging procedures}

\section{FRI0622 JOINT TENDERNESS AND ULTRASOUND INFLAMMATION IN EARLY RHEUMATOID ARTHRITIS PATIENTS INCLUDED IN THE ARCTIC TRIAL}

nina sundlisater ${ }^{1}$, Anna-Birgitte Aga ${ }^{1}$, Hilde Berner Hammer ${ }^{1}$, Till Uhlig ${ }^{1,2}$, Tore K. Kvien ${ }^{1,2}$, Espen Haavardsholm ${ }^{1,2}$, Siri Lillegraven ${ }^{1}{ }^{1}$ Diakonhjemmet Hospital, Oslo, Norway; ${ }^{2}$ University of Oslo, Faculty of Medicine, Oslo, Norway

Background: A tender joint count is part of most disease activity scores and remission criteria in rheumatoid arthritis (RA). A recent study found that tender joint count might not reflect inflammatory activity, assessed by ultrasound, in established RA (1).

Objectives: To explore if tender non-swollen joints is associated with subclinical inflammation, assessed by ultrasound, in DMARD-naïve early RA patients.

Methods: DMARD-naïve RA patients with $<2$ years symptom duration from first swollen joint and indication for DMARD treatment were included in the ARCTIC trial (2). For the current analyses we used data from the baseline examination, including a tender joint count assessed by Ritchie Articular Index and a 44-swollen joint count. The Ritchie Articular Index treat certain joints as a single unit (as the MCP-joints), and scoring of tenderness in joints and joint groups is graded 0-3. All patients underwent an ultrasound examination of 34 joints, with a semi-quantitative 0-3 score for power Doppler in each joint. An ultrasound atlas was available for reference (3). We predefined the wrist and the MCP 1-5 joints as joint areas of interest since they are commonly involved in RA and were assessed both clinically and by ultrasound. We selected only joints that were clinically non-swollen, and assessed the association between joint tenderness and ultrasound power Doppler signal by mixed logistic regression models with patient-specific intercept to adjust for within-patient dependencies. The analyses were repeated using generalized estimating equations for robustness. The frequency and odds ratio (OR) of ultrasound power Doppler activity (yes/no) in tender non-swollen wrists compared to non-tender non-swollen wrists were calculated. Similar analyses were performed for the MCP joints.

Results: A total of 222 patients with complete baseline data were included. $63 \%$ were female, median [SD] age 53.6 [41.2, 62.3], symptom duration $5.8[2.9,10.4]$ months, swollen joint count $9[4,15]$, joint tenderness $7[4,13]$ and power Doppler score $7[3,14]$. Of 444 wrists, 268 were not swollen. The frequency of power Doppler signal $>0$ in tender non-swollen wrists were $50 \%(18 / 36)$, compared to $23 \%(53 / 232)$ in nontender non-swollen wrists $(\mathrm{p}$-value for comparison $=0.001)$. This corresponds to an OR of $4.32(95 \% \mathrm{Cl} 1.47$ to $12.65, \mathrm{p}=0.008)$ for power Doppler signal if the wrist is tender but not swollen, compared to a nontender non-swollen wrist. Similar results were found for the non-swollen MCP-joints (Table).

Table:. The frequency and odds ratio (OR) of ultrasound power Doppler (PD) activity in Ritchie positive versus Ritchie negative non-swollen wrists and MCP joints.

\begin{tabular}{lcccc}
\hline & $\begin{array}{c}\text { PD-signal positive if } \\
\text { Ritchie positive }\end{array}$ & $\begin{array}{c}\text { PD-signal positive if } \\
\text { Ritchie negative }\end{array}$ & OR (Cl) & $\begin{array}{c}\text { p- } \\
\text { value }\end{array}$ \\
\hline $\begin{array}{l}\text { Non-swollen } \\
\text { wrist, } \mathbf{n = 2 6 8}\end{array}$ & $18 / 36(50 \%)$ & $53 / 232(23 \%)$ & $\begin{array}{l}4.32(1.47 \\
\text { to } 12.65)\end{array}$ & 0.008 \\
$\begin{array}{l}\text { Non-swollen MCP } \\
\text { joints, } \mathbf{n = 1 6 5}\end{array}$ & $15 / 35(43 \%)$ & $28 / 130(22 \%)$ & $\begin{array}{r}4.84(1.31 \\
\text { to } 17.89)\end{array}$ & 0.02 \\
\hline
\end{tabular}

Conclusion: Ultrasound power Doppler activity was more frequent in nonswollen wrists and non-swollen MCP joints if the joints had been scored as tender or painful by Ritchie Articular Index. Our findings indicate that in early RA patients, tenderness might reflect inflammation which is not detectable clinically.

\section{REFERENCES:}

[1] Hammer HB, et al. Arthritis care \& research. 2018.

[2] Haavardsholm EA, et al. BMJ. 2016;354.

[3] Hammer HB, et al. ARD. 2011;70(11).

Disclosure of Interests: nina sundlisater: None declared, Anna-Birgitte Aga Consultant for: UCB, AbbVie, and Pfizer, Paid instructor for: UCB, Hilde Berner Hammer Grant/research support from: AbbVie, Pfizer and Roche, Paid instructor for: AbbVie, Pfizer, UCB, Novartis, Roche, Speakers bureau: AbbVie, Pfizer, UCB, Novartis, Roche, Till Uhlig Consultant for: Grünenthal, Novartis, Speakers bureau: Grünenthal, Novartis, Tore K. Kvien Grant/research support from: AbbVie, BMS, MSD, Pfizer, Roche and UCB., Consultant for: AbbVie, Biogen, BMS, Boehringer Ingelheim,
Celgene, Celltrion, Eli Lilly, Hospira, Merck-Serono, MSD, Novartis, Oktal, Orion Pharma, Pfizer, Roche, Sandoz, Sanofi, Mylan and UCB, Speakers bureau: AbbVie, Biogen, BMS, Boehringer Ingelheim, Celgene, Celltrion, Eli Lilly, Hospira, Merck-Serono, MSD, Novartis, Oktal, Orion Pharma, Pfizer, Roche, Sandoz, Sanofi and UCB, Espen Haavardsholm Grant/ research support from: Pfizer, UCB, Roche, MSD, and AbbVie, Consultant for: Pfizer, Paid instructor for: Pfizer, Speakers bureau: Pfizer, UCB, Roche, and AbbVie, Siri Lillegraven: None declared

DOI: 10.1136/annrheumdis-2019-eular.4657

\section{FRI0623 MRI-DETECTED DIGIT FLEXOR TENOSYNOVITIS IN BILATERAL PROXIMAL INTERPHALANGEAL JOINTS CONTRIBUTE TO JOINT TENDERNESS IN PATIENTS WITH EARLY RHEUMATOID ARTHRITIS}

YingQian Mo ${ }^{1}$, Ze-Hong Yang ${ }^{2}$, Jun-Wei Wang ${ }^{1}$, LI Qian-Hua ${ }^{1}$, Xin-Yun Du' ${ }^{1}$, YanHui Xu1 ${ }^{1}$, Kui-Ming Yang ${ }^{1}$, Guang-Zi Shi ${ }^{2}$, Jun Shen ${ }^{2}$, Lie Dai ${ }^{1} .{ }^{1}$ Sun Yat-Sen Memorial Hospital, Sun Yat-Sen University, Department of Rheumatology, Guangzhou, China; ${ }^{2}$ Sun Yat-Sen Memorial Hospital, Sun Yat-Sen University, Department of Radiology, Guangzhou, China

Background: Independent predictive value of ultrasonography-detected digit flexor tenosynovitis has been reported for rheumatoid arthritis (RA) development in patients with early arthritis, and it also was reported as an independent risk factor of flare in remission RA. However, proximal interphalangeal joints (PIPJs) were scarcely evaluated by MRI, nor recommended by RAMRIS so far.

Objectives: To explore the characteristics of MRI-detected inflammation in bilateral PIPJs in early RA patients and its clinical significance.

Methods: Early RA patients who fulfilled 2010 ACR/EULAR classification criteria with disease duration $\leq 1$ year and DAS28-CRP $\geq 2.6$ were recruited. New methodology of $3.0 \mathrm{~T}$ whole-body MRI with contrastenhanced imaging was used to scan bilateral hands simultaneously. MR tenosynovitis, synovitis and osteitis were scored referring to the 2016 updated RAMRIS. Clinical data were collected.

Results: 1) Among 75 patients recruited, the median age was 49 years old (IQR: 38-59) with $71 \%$ female. The median disease duration was 7 months (IQR: 3-12) and the mean DAS28-CRP was 5.1 (IQR: 4.2-6.1). Forty-four patients $(59 \%)$ were treatment-naïve who had never taken any DMARDs or glucocorticoids before recruitment. Both joint tenderness and swelling were present the most frequently in PIPJ2 and PIPJ3 $(48 \% 61 \%$ and $43 \% 56 \%$, respectively, Figure $1 \mathrm{~A}$ ).2) MRI tenosynovitis, synovitis and osteitis were detected in $84 \%, 100 \%$ and $83 \%$ of the patients; and respectively in $21 \% 44 \%, 43 \% 56 \%$ and $5 \% 11 \%$ of various PIPJs. There were $12 \% 30 \%, 28 \% 40 \%$, and $2 \% 8 \%$ of PIPJs without tender or swollen showing MRI tenosynovitis, synovitis and osteitis respectively. When nondominant hands were used as self-control, the frequency of digit flexor tenosynovitis in dominant interphalangeal joint (IPJ) of thumb, PIPJ2 and PIPJ4 was $16 \% 18 \%$ higher than the non-dominant counterparts, indicating a potential impact of overuse on dominant tenosynovitis. 3) Tenosynovitis affects periarticular digit flexor tendon compartment and $65 \% 87 \%$ of tenosynovitis in PIPJs occurred together with synovitis in joint cavity and/or osteitis in subchondral bone. Among tender IPJ of thumb, $50 \%$ of them showed MRI synovitis together with digit flexor tenosynovitis, which was significantly more than those who showed MRI synovitis alone $(21 \%$, Chisquare test, $p<0.017)$. Similar trend was found in tender PIPJ2 $(45 \%$ vs $26 \%, p<0.01)$. Generalized Estimating Equations with multivariate logistic regression showed not only MRI synovitis but also digit flexor tenosynovitis in bilateral PIPJs independently had more than twice probability of joint tenderness (both $p<0.01$, Figure $1 \mathrm{~B}$ ). 